\title{
A investigação em serviços de saúde e a pandemia de COVID-19
}

Escrevo este Editorial num momento de luto no Brasil. Luto pelas pessoas que já faleceram em nosso país em decorrência da pandemia de COVID-19. Luto, por saber que parte desses óbitos poderiam ter sido evitados. Luto, por termos um governo que se volta para o desmonte do Estado brasileiro, que se omite em meio à pandemia, assumindo postura negacionista, se omitindo em relação às suas responsabilidades, adotando atitudes enganosas e desinformadas na comunicação com a população. A estrutura de governança do Sistema Único de Saúde (SUS), desenvolvida com sucesso ao longo de muitos anos, foi deixada de lado numa intencional e inexplicável ação governamental que parece querer deixar a epidemia seguir o seu curso quase que natural.

Em contraponto à omissão do Governo Federal, alguns governos locais, profissionais de saúde, especialistas das mais diversas áreas do conhecimento, parlamentares, juristas e movimento social se engajaram no debate e na luta pela mitigação dos efeitos da pandemia. Imbuídas por esses motivos, entidades organizadas na Frente pela Vida, com a liderança da Associação Brasileira de Saúde Coletiva (Abrasco), lançaram o Plano Nacional de Enfrentamento à COVID-19 1. São planos, propostas e debates que entre outros aspectos trouxeram para o centro das atenções os serviços e os sistemas de saúde. A oferta de leitos de UTI, de ventiladores mecânicos, o papel da atenção primária de saúde, a disponibilidade de equipamentos de segurança individual e a eficácia dos medicamentos na profilaxia e tratamento da COVID-19 tornaram-se preocupações da sociedade, escapando dos limites dos especialistas para serem por todos debatidas.

A pandemia causada pelo SARS-CoV-2 faz com que os sistemas de saúde passem, de um momento para o outro, a ter de lidar com uma demanda crescente, em alguns casos extremamente alta, de pacientes graves, portadores de doença altamente contagiosa, com quadro clínico desconhecido e sem tratamento disponível. Sem que se adotem medidas de controle adequadas, a velocidade de transmissão do vírus pode gerar para os serviços de saúde uma demanda de pacientes em volume insuportável, principalmente daqueles de maior complexidade, mesmo para os sistemas de saúde de países desenvolvidos. Pode também ocasionar muitos óbitos por ser a COVID-19 uma doença de alta letalidade, quando comparada a outras síndromes gripais. A expansão de pontos de cuidado e sua reorganização numa linha
1 Instituto de Comunicação e Informação Científica e Tecnológica em Saúde Fundação Oswaldo Cruz, Rio de Janeiro, Brasil. 
de cuidado específica, articulada à rede de atenção à saúde, mostra-se necessária para aumentar a efetividade do sistema e salvar vidas 2 .

Por tratar-se de uma doença desconhecida, trouxe consigo desafios aos mais diversos âmbitos de ação, dentre eles, à área de investigação em serviços de saúde. Desde o início da pandemia o esforço da ciência na identificação e desenvolvimento de esquemas terapêuticos e preventivos eficazes e seguros ocorre numa velocidade e intensidade nunca vistos. Os preceitos de Dr. Archie Cochrane, médico inglês que, no início da década de 1970, chamou a atenção para a importância de se conhecer a eficácia (denominada "efetividade" pelo autor) dos procedimentos de saúde por meio de ensaios clínicos controlados, abrindo caminho para o surgimento da Avaliação de Tecnologias em Saúde (ATS) e da Medicina Baseada em Evidência, ganharam destaque em todo o mundo. Cochrane em seu famoso livro Effectiveness er Efficiency: Random Reflections on Health Services ${ }^{3}$, atentou para o grau de desinformação existente na sociedade naquela época, tal como hoje em dia, em que muitas pessoas não distinguiam a opinião de evidência científica, ao enfatizar a importância desta para a adoção de novos procedimentos no cotidiano do cuidado de saúde. Destacou a relevância da avaliação em saúde para orientar a decisão profissional e garantir efetividade ao cuidado de saúde, diminuindo o sofrimento, as sequelas e salvando vidas. Suas reflexões sobre a eficácia foram além dos procedimentos preventivos, diagnósticos e terapêuticos ao incorporarem a organização dos serviços de saúde e o processo de cuidado. Tratou também da questão da igualdade social e territorial no cuidado de saúde, trazendo à baila temas estruturantes da investigação em serviços de saúde que hoje perpassam os debates sobre os desafios envolvidos na mitigação dos danos causados pela pandemia.

No Espaço Temático deste fascículo sobre a avaliação em saúde são publicados artigos 4,5,6 cujos autores representam renomados pesquisadores. Neles podemos apreender os caminhos percorridos pela pesquisa nesta área do conhecimento, particularmente a partir da segunda metade do século passado quando autores seminais começaram a publicar seus trabalhos, como seguir as reflexões e críticas que fazem sobre o futuro da pesquisa. Vale ressaltar que os artigos foram escritos antes da pandemia e, portanto, não incorporam os possíveis impactos que esta, dada a sua magnitude e poder de mudança, deverá ter sobre a saúde em geral e a investigação em serviços de saúde, em particular.

Destaco o privilégio que representa para Cadernos de Saúde Pública incluir neste fascículo o texto autobiográfico de David Banta 7, um dos fundadores da ATS e valioso colaborador do Brasil. Banta nos conta, dentre outros relatos que envolvem seus trabalhos e as amizades que conquistou no país, sobre o seu frutífero encontro com Cochrane nos Estados Unidos e o impacto que este teve sobre o surgimento da ATS.

Lilia Schraiber, debatedora convidada, leu o conjunto de artigos como uma historiografia da investigação em serviços de saúde 8 . Em sua análise, percebe uma tendência histórica à segmentação do seu objeto, os serviços de saúde, que implica o risco de estes passarem a ser vistos como objetos fora do mundo social que os define. Assim, ao tempo em que a complexidade do cuidado de saúde abre espaço para vertentes diversas de investigação, somos instigados a retomar o significado dos serviços de saúde em sua intrincada relação com a sociedade.

Estamos em um momento da história em que não podemos desconsiderar que novas crises sanitárias venham a somar-se à atual crise climática. Esses eventos, de gravidade imprevisível, clamam, indiscutivelmente, no sentido do fortalecimento de sistemas e serviços de saúde universalmente acessíveis, integrados, seguros e com ampla e ágil capacidade de 
resposta. As transformações em curso nos sistemas e serviços de saúde afetarão os ambientes de cuidado e podem ocasionar o agravamento das desigualdades sociais e territoriais no acesso a cuidado de saúde efetivo. Os grandes negócios que cada vez mais envolvem o desenvolvimento e a comercialização de equipamentos, medicamentos e imunobiológicos 9 apontam para o aumento do gap entre necessidades de saúde e oferta de cuidados de saúde. São as sociedades democráticas, que valorizam e fortalecem a ciência, que melhor poderão se organizar para responder às incertezas do futuro de modo a preservar vidas.

\section{Informação adicional}

ORCID: Claudia Travassos (0000-0002-47898511).

1. Associação Brasileira de Saúde Coletiva. Abrasco e demais entidades da saúde lançam Plano Nacional de Enfrentamento à COVID-19. https://www.abrasco.org.br/site/noticias/es pecial-coronavirus/abrasco-e-demais-entida des-da-saude-lancam-plano-nacional-de-en frentamento-a-covid-19/49795/ (acessado em Ago/2020)

2. Portela MC, Grabois V, Travassos C. Matriz linha de cuidado Covid-19 na rede de atenção à saúde. https://portal.fiocruz.br/documento/ matriz-linha-de-cuidado-covid-19-na-rede-de -atencao-saude (acessado em Ago/2020).

3. Cochrane AL. Effectiveness \& eficiency: random reflections on health services. 2 nd Ed. London: Royal Society of Medicine Press Limited; 1972.

4. Vieira-da-Silva LM, Furtado JP. A avaliação de programas de saúde: continuidades e mudanças. Cad Saúde Pública 2020; 36:e00237219.
5. Martins M, Portlea MC, Noronha MF. Investigação em serviços de saúde: alguns apontamentos históricos, conceituais e empíricos. Cad Saúde Pública 2020; 36:e00006720.

6. Novaes HMD, De Soárez PC. A Avaliação das Tecnologias em Saúde: origem, desenvolvimento e desafios atuais. Panorama internacional e Brasil. Cad Saúde Pública 2020; 36:e00006820.

7. Banta D. Brazil and my life in Health Technology Assessment. Cad Saúde Pública 2020; 36:e00055420.

8. Schraiber LB. Desenvolvimento da avaliação em saúde: percursos e perspectivas. Cad Saúde Pública 2020; 36:e00163820.

9. Prabhala A, 't Hoen E. We'll find a treatment for coronavirus - but drug companies will decide who gets it. The Guardian 2020; 15 abr. https:// www.theguardian.com/commentisfree/2020/ apr/15/coronavirus-treatment-drug-compa nies. 